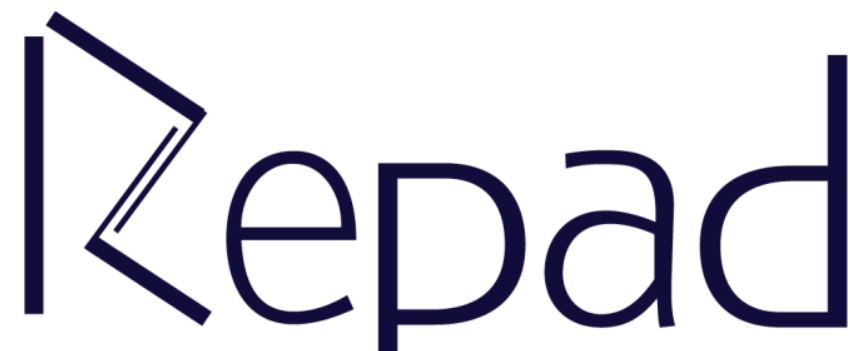

Vol. 2, n. 3, Dezembro/2018

Revista Estudos e

Pesquisas em Administração

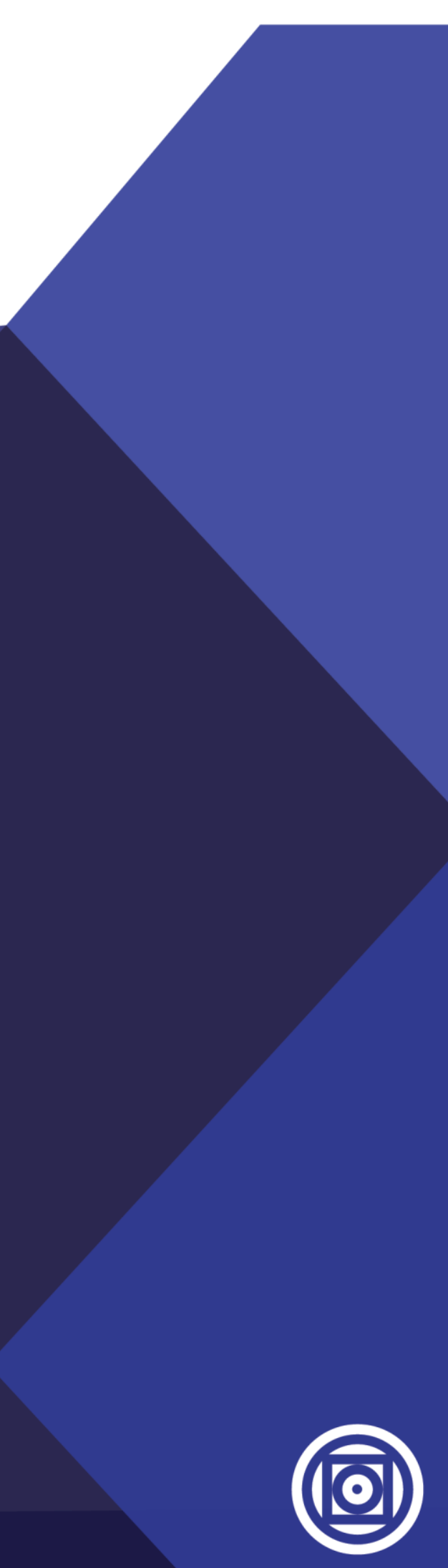




\title{
BALANCED SCORECARD: avaliação de uma proposta de uma empresa de siderurgia
}

André Matheus Mella de Paulo Universidade Federal de Mato Grosso https://orcid.org/0000-0003-4782-056X

João Bosco Arbués Carneiro Júnior Universidade Federal de Mato Grosso https://orcid.org/0000-0001-7094-2245

Sofia Ines Niveiros

Universidade Federal de Mato Grosso http://orcid.org/0000-0001-6547-5881

\section{RESUMO}

Atualmente, as empresas estão buscando constantemente informações que auxiliem na tomada de decisões e análise das ações adotadas, procurando sempre diferenciais e oportunidades disponíveis que ajudem na medição e interpretação das informações que se obtém. Este trabalho busca responder a seguinte questão: Quais perspectivas que compõem o Balanced Scorecard da empresa de siderurgia analisada refletem a proposta desenvolvida por Kaplan e Norton? O objetivo desse estudo é analisar se o Balanced Scorecard da empresa XYZ foi desenvolvido conforme a metodologia de Kaplan e Norton, fazendo isso com as informações disponibilizadas pela empresa, levando em consideração toda a estrutura apresentada. Quanto a metodologia a pesquisa foi descritiva, estudo de caso, qualitativa e sendo corte transversal. Na fundamentação foram discutidos tópicos relevantes da pesquisa como: planejamento estratégico, estratégias empresariais, modelo de Porter, Balanced Scorecard, perspectiva de aprendizado e crescimento, perspectiva de processos internos, perspectiva de clientes, perspectiva financeira e mapas estratégicos. Diante das análises verificou-se que a metodologia utilizada pela empresa XYZ se encaixa na proposta de Kaplan e Norton.

Palavras-chave: Balanced Scorecard. Estratégia. Sistema de Gestão.

\section{BALANCED SCORECARD: evaluation of a proposal from a steel company}

\begin{abstract}
Today, companies are constantly seeking information that helps them to make decisions and analyze the actions they take, always looking for differentials and opportunities available that help in the measurement and interpretation of the information that is obtained. This paper seeks to answer the following question: Which perspectives that make up the Balanced Scorecard of the steel company analyzed reflect the proposal developed by Kaplan and Norton? The objective of this study is to analyze whether the Balanced Scorecard of the company XYZ was developed according to the methodology of Kaplan and Norton, doing this with the information made available by the company, taking into account the whole structure presented. Regarding
\end{abstract}


the methodology the research was descriptive, case study, qualitative and being cross-sectional. Relevant research topics such as: strategic planning, corporate strategies, Porter model, Balanced Scorecard, learning and growth perspective, internal process perspective, client perspective, financial perspective and strategic maps were discussed. In view of the analyzes, it was verified that the methodology used by the company XYZ fits in the proposal of Kaplan and Norton.

Keywords: Balanced Scorecard. Strategy. Management system.

\section{INTRODUÇÃO}

O mundo está em constante mudança, assim atualizar o modo de gerenciar as empresas e analisar as metas é algo primordial para se manter competitivo no mercado. O Balanced Scorecard (BSC) surgiu para auxiliar esse novo modo de ver as metas e como alcançá-las. Segundo Lunkes et al (2009), o BSC auxilia as empresas como instrumento gerencial, possibilitando efetuar seus controles de processos por meio de medições de desempenho em sintonia com o planejamento estratégico.

O BSC trabalha com quatro vertentes como base para o desenvolvimento do planejamento estratégico: (financeira, clientes, processos internos; e aprendizado e crescimento), sendo estes necessários para a implementação de uma gestão baseada no BSC (COSTA, 2008). Desta forma se estabeleceram quais são os pontos que devem ser elaborados e estudados para a implantação de um sistema de gestão, sendo necessário conhecimento em cada uma das áreas para que estas sejam desenvolvidas ao máximo para um melhor aproveitamento das informações propiciadas pelo mesmo.

Analisando as perspectivas em que o sistema de gestão trabalha, nota-se que estão direta ou indiretamente interligados, pois quando se trabalha o aprendizado e crescimento dos colaboradores, o impacto dentro dos processos internos da empresa aparecem, os clientes recebem seu produto ou serviço com a qualidade desejada, sendo isso reflexo de conhecimento que foi agregado aos profissionais e o resultado que os proprietários e sócios mais desejam fica evidente no processo financeiro, tornando isso um ciclo dentro da empresa.

O BSC é um modelo de gestão, pois trabalha com medidas de desempenho que são úteis a qualquer empresa para se tomar um direcionamento com base nas informações apresentadas por ele (KIYAN, 2001; HIKAGE; SPINOLA; LAURINDO, 2006). Kaplan e Norton (1997, p. 2), destacam que: "O Balanced Scorecard (BSC) oferece a esses executivos os instrumentos de que necessitam para alcançar o sucesso no futuro". A competitividade torna fundamental que as empresas tenham uma perfeita compreensão de suas metas e dos métodos para alcançá-las (KAPLAN; NORTON, 1997). O mundo hoje exige das empresas atualização constante, que se adaptem ao mercado, desde a compra de insumo até a venda do produto acabado, para fazer isso o corpo responsável pela gestão da corporação precisa de ter uma visão interna e externa do ambiente que ela se encontra instalada, e isso se dá por meio de instrumentos de gestão e de análise.

Para que esse processo mostre resultados positivos todos os profissionais da empresa precisam estar empenhados em todos os níveis da instituição, desde os operários da linha de frente ate os executivos que tomam as decisões (KAPLAN; NORTON, 1997). Todas as decisões que forem tomadas devem ser comunicadas entre todos da organização e em todos os níveis, pois isso garante um comprometimento coletivo em prol dos mesmos objetivos e metas que foram estabelecidos (MORIM, 2016). 
Segundo Instituto Aço Brasil (2015), o setor de siderurgia no Brasil hoje é representado por 14 empresas privadas, sendo dividido em 11 grupos empresariais que operam 29 usinas em território brasileiro, gerando um saldo comercial de U\$3,5 bilhões no ano de 2015 e gerando mais de 100mil empregos nessa área da economia. A empresa analisada desenvolveu um modelo de gestão baseado na proposta de Kaplan e Norton, elaborando um planejamento de gestão estratégica, tornando-se um BSC aplicado.

Diante das informações expostas, pretende-se responder com esta pesquisa a seguinte questão: Quais perspectivas que compõem o Balanced Scorecard da empresa de siderurgia analisada refletem a proposta desenvolvida por Kaplan e Norton? Desta forma, o estudo objetiva analisar se o Balanced Scorecard apresentado pela empresa XYZ de siderurgia encontra-se em conformidade com a metodologia proposta por Kaplan e Norton.

A relevância da pesquisa reside no fato de que permite à empresa objeto deste estudo comparar o modelo implantado com a literatura, especialmente ao que foi proposto pelos idealizadores do sistema de gestão BSC.

Para a empresa em questão, por ela já ter um plano estratégico com a elaboração de um sistema de gestão baseado no BSC, é viável e importante fazer uma verificação para identificar se o mesmo está em conformidade com as propostas de Kaplan e Norton. Com este trabalho será possível ver os pontos de melhoria no planejamento da empresa proporcionando possibilidades de mudanças e adaptações ao planejamento adotado.

\section{FUNDAMENTAÇÃO TEÓRICA}

\section{Planejamento Estratégico}

Com as constantes mudanças que ocorrem no mercado, a competitividade das empresas em todos os setores obriga as mesmas a buscarem inovações, ferramentas para manter-se à frente dos concorrentes. A busca por meios de auferir uma vantagem no mercado requer um planejamento, para Ribeiro (2001) planejamento é um processo que especifica que deve ser feito para atingir um objetivo específico. $\mathrm{O}$ ato de fazer um planejamento requer conhecer os passos necessários para alcançar as metas que foram estabelecidas.

Num planejamento empresarial ter uma estratégia agregada a essa ferramenta auxilia muito a visão para um futuro mais longevo. Oliveira (2006, p. 47) define planejamento estratégico (PE) como "o processo administrativo que proporciona sustentação metodológica para se estabelecer a melhor direção a ser seguida pela empresa, visando ao otimizado grau de interação com o ambiente e atuando de forma inovadora e diferenciada".

Quando se molda um processo administrativo adequado à empresa e ao mercado que se encontra, fazer o planejamento, a análise do ambiente e a demonstração de inovações na gestão facilita a gestão dos administradores.

Oliveira (2006) estabelece que para fazer a implantação do PE se deve seguir quatro fases: diagnóstico estratégico, missão da empresa, instrumentos prescritivos e quantitativos e controle e avaliação; essas etapas devem ser implementadas na empresa para que a execução e o resultado sejam o mais consistente possível.

\section{Estratégia Empresarial}

A estratégia empresarial consiste em um instrumento para as empresas conseguirem formular suas decisões. Para que a entidade consiga se manter no mercado e ainda obter um diferencial frente a concorrência, ela precisa de estratégias, que são elaboradas com base nas informações que a empresa possui, informações essas que podem ser de mercado, financeira, de produção, entre outras. Segundo Costa (2008, p. 12) "A estratégia tem que estar definida 
claramente, para que se possa chegar a um consenso sobre as metas essenciais ao cumprimento da estratégia". Trabalhar com ideias claras, que mostrem realmente quais são os projetos, as etapas e atitudes que devem ser tomadas, facilita a análise e consequentemente a execução e resultados da empresa.

Fazendo a identificação de quais estratégias devem ser adotadas para melhorar a relação com clientes, fornecedores e funcionários, é possível detectar quais processos podem estar interferindo em um sistema que busca a excelência. Quando se faz esse levantamento podemse adaptar estratégias para solucionar as interferências e seguir buscando sempre atingir a excelência na estratégia (KAPLAN; NORTON, 1997).

Quando se pensa em fazer a formulação da estratégia, deve-se levar em conta o ambiente que se encontra a organização, fazendo desse ambiente seu foco para que as decisões que sejam traçadas consigam atender completamente as necessidades e saibam lidar com os acontecimentos externos e internos que surgirão com o decorrer do tempo, levando em consideração as cinco forças competitivas (PORTER, 2004).

Formular a estratégia empresarial mais adequada para cada empresa, levando em consideração mercados e as limitações e políticas que são adotadas é um dos pontos que deve ser levantado e colocado em relatório para se definir objetivos, considerar fatores internos e externos à organização, facilita o entendimento do conjunto e possibilita uma visão ampla dos acontecimentos e proporcionalmente um melhor posicionamento para tomada de decisão.

\section{O modelo de Porter}

Uma técnica de elaboração do PE criada com intuito de auxiliar no aumento do lucro e manter a empresa firme no seu mercado é o modelo de Michael Porter de 1979. Denominado "Cinco forças competitivas" surgiu com a intenção de auxiliar as instituições na verificação da concorrência nos mercados em que as empresas se encontram. Porter $(2004$, p. 3$)$ explica que "O grau da concorrência em uma indústria depende de cinco forças competitivas básicas, [...]. O conjunto dessas forças determina o potencial de lucro final na indústria, que é medido em termos de retorno a longo prazo sobre o capital investido".

As cinco forças que Porter definiu são: ameaças de novos entrantes, poder de negociação dos clientes, ameaça de produtos ou serviços substitutos, poder de negociação dos fornecedores e rivalidade entre as empresas existentes (PORTER, 2004).

No que se refere à ameaça de novos entrantes, isso só será permitido caso as barreiras que são criadas: economia de escala, diferenciação do produto, necessidade de capital, custos de mudança, acesso aos canais de distribuição, desvantagens de custo independentes de escala, política governamental; caso todas essas barreiras estejam altas, quando alguma ameaça for detectada, ela sofrerá uma retaliação por parte dos concorrentes, sendo isso uma demonstração de defesa (PORTER, 2004). Quanto à rivalidade entre as empresas existentes, esse tipo de acontecimento é normal em todos os mercados, entretanto empresas que fazem um planejamento, prevendo quais concorrentes podem se destacar e lançar novos produtos ou promoções é possível minimizar o impacto do concorrente.

Porter (2004) define os produtos substitutos como aqueles que reduzem os retornos potenciais. Fazendo a análise do impacto que um produto substituto pode causar dentro do resultado de uma ou várias empresas do segmento, fica claro que as organizações devem fazer um monitoramento para quantificar qual está sendo a influência no mercado e nos clientes.

Referente a negociação dos fornecedores, para Porter (2004) os compradores conseguem adquirir algumas vantagens com os compradores, fazendo que eles façam uma disputa pelo cliente, consequentemente o valor do produto tende a diminuir, a qualidade aumenta e os serviços de diferencial surgem para agregar valores aos produtos. Fazer 
monitoramento dos compradores pode ajudar a empresa em um futuro mapeamento de quais pontos podem estar sendo levando em conta no mercado, com isso pode-se conseguir medir e ver qual estratégia pode ser adotada para se conseguir melhorar nesse aspecto.

Para Porter (2004), o comprador pode se tornar poderoso, porém para que isso ocorra, deve ter conquistado as seguintes circunstâncias com veracidade: adquirir grandes volumes, comprar produtos padronizados, não ficar preso a um fornecedor por causa dos custos, trabalhar com um lucro baixo para forçar o fornecedor a baixar o seu preço, ter total informação acerca do produto, entre outras circunstâncias que causam um impacto na hora de fazer a negociação.

Porter (2004) diz que para o fornecedor conseguir se tornar poderoso frente a seus clientes, que necessitam do seu produto, se os seguintes itens forem alcançados: quando o fornecedor não trabalha com um único produto, conseguindo atender várias áreas gerando uma influência em cada uma delas; sempre que o fornecedor não precisar lutar com um produto substituto, ele consegue uma vantagem perante o comprador; caso seu cliente não seja seu único comprador e a parte que determinado cliente tem da sua participação nas vendas não seja relativamente alta, o fornecedor consegue um ganho; quando o produto que o fornecedor entrega é primordial para a produção dos produtos de determinada empresa, o fornecedor tem o comprador retido a sua empresa; ter o poder de limitar o crescimento das empresas para manter o poder de compra dela, submisso ao desejado, é uma vantagem que afeta muito o empresário, porém para o fornecedor é uma vantagem muito grande.

Braga, Almeida e Silva (2005) pesquisaram a importância do BSC como base de medição e gestão estratégica de custos, sendo um estudo de caso aplicado ao Setor de Turismo de Campina Grande-PB. Destacando o PE examinado pelos autores, desenvolvendo estratégias de elaboração e execução do planejamento, fazendo o trabalho com base nas cinco forças competitivas de Porter. Foi evidenciada a análise de novos entrantes ao mercado regional, a negociação com fornecedores, com os compradores, produtos substitutos que surgem constantemente e podem gerar impacto no turismo da região e a rivalidade entre os concorrentes no município, desenvolvendo junto com as forças de Porter o BSC. Este foi desenvolvido e aplicado a empresa de turismo Golden Tour International, empresa que mais atende turistas na região, chegando a conclusão do artigo que as cinco forças estão sobre controle da empresa, porém, podendo ser desenvolvido um trabalho especial com os fornecedores para a obtenção de um maior lucro.

Nota-se que o modelo de Porter, possibilita que as empresas consigam fazer um mapeamento e uma análise dos pontos em que ela tem vantagem perante seus concorrentes e quais ela deve repensar e tomar decisões para não ser afetada pelas mudanças do mercado.

\section{Balanced Scorecard - BSC}

Desenvolvido por Robert Kaplan e David Norton nos Estados Unidos, na década de 90, com o intuito de ser um sistema de medida para avaliar o desempenho dando uma visão da real situação da empresa. Para Kaplan e Norton (1997) o BSC complementa as medidas financeiras do desempenho passado com medidas dos vetores que impulsionam o desempenho futuro. $\mathrm{O}$ BSC foi desenvolvido a partir da percepção de que só os indicadores financeiros não forneceriam todas as informações e dados necessários para uma boa gestão.

Segundo Kallás (2003), Kaplan e Norton anos depois de lançarem o BSC, notaram que ele se encaixava como um modelo de gestão estratégica e não como um medidor de desempenho, essa nova classificação foi aceita com algumas ressalvas no meio empresarial.

A pesquisa de Lunkes et al. (2009), aplicada a uma empresa de software, visa demonstrar qual pode ser a contribuição do BSC para a empresa, que sente a necessidade de um método para avaliação de seus objetivos. Para se construir o BSC utilizou-se de reuniões 
para ser definido qual sistema seria utilizado. Após a definição, desenvolveram um mapa estratégico tendo como base as quatro perspectivas do BSC. No desenvolvimento do projeto foi utilizado o planejamento estratégico que foi construído, análises, mapa estratégico, indicadores e metas. Conforme Kaplan e Norton (1997), o BSC cria dentro da empresa sua estrutura, meios de comunicação que expressarão a missão e a estratégia, e utiliza os indicadores para fazer a divulgação aos funcionários.

Para Lunkes et al. (2009, p. 3), o Balanced Scorecard é "[..] um conjunto de medidas de desempenho que são derivadas da estratégia da organização. Assim, essas medidas direcionam, monitoram e avaliam a evolução dos objetivos estratégicos da organização". Obter os dados e analisá-los é um meio de fazer o monitoramento do desempenho da empresa, com base nessas informações, são tomadas as decisões futuras e se consegue visualizar quais objetivos estão sendo alcançados com as políticas adotadas.

O BSC utiliza indicadores e perspectivas, que não são apenas financeiras, com isso se consegue agregar ainda mais a gestão e a avaliação do desempenho da empresa, pois tendo mais dados e informações, os gestores conseguem determinar um melhor posicionamento diante das metas e objetivos que foram definidos. O BSC é um sistema de gestão que não fica apenas restrito aos diretores da empresa, ele pode alcançar todos os funcionários, fazendo eles se sentirem parte da empresa, com responsabilidades sobre os resultados que virão com a implantação do Balanced Scorecard.

Conforme Wernke, Borniar (2001), quando se parte para a estratégia da empresa utilizando uma visão mais abrangente do sistema, a instituição consegue estruturar quatro perspectivas: financeira, clientes, processos internos e aprendizado e crescimento. Dada à relevância das perspectivas é conveniente descrevê-las a seguir.

Perspectiva de Aprendizagem e Crescimento

A perspectiva de aprendizado e crescimento trata mais do humano, do conhecimento, com o objetivo de ser um orientador para o crescimento da organização. Buscando fazer a análise de quais pontos podem ser mudados para melhorar o desempenho futuro, sempre se adequando a realidade do mercado inserido. Kaplan e Norton (1997, p.131 apud KALLÁS, 2003, f. 68) "o objetivo da perspectiva de aprendizado e crescimento oferecem a infraestrutura que possibilita a consecução de objetivos ambiciosos nas outras três perspectivas". Para Kaplan e Norton (1997) fazer uma identificação da infraestrutura que a empresa dispõe e analisar se ela é apta a suportar o crescimento e as melhorias que serão realizadas com a implantação do BSC, é um dos pontos que cabe a perspectiva de aprendizagem e crescimento.

$\mathrm{Na}$ concepção de Costa (2008, p. 35) "as empresas melhorem, constantemente, seus produtos e seus processos e tenham a habilidade para introduzir produtos inteiramente novos, é necessário captar, mediante indicadores". A perspectiva de aprendizado e crescimento vem com intuito de mostrar quais pontos estão passando em branco e quais estão adequados ao modelo proposto no planejamento estratégico, trabalhando o intelectual das pessoas, com isso, funcionários e diretores conseguem notar que uma melhor estrutura e capacitações constantes aos empregados, eles desenvolvem suas atividades com mais agilidade e com mais zelo.

Segundo Kaplan e Norton (1997, p. 29), "o aprendizado e o crescimento organizacionais provêm de três fontes principais: pessoas, sistemas e procedimentos organizacionais". "No caso do Balanced Scorecard, a ênfase, como não poderia deixar de ser, é com a capacitação do funcionário, ou, em outras palavras, com o capital humano e intelectual, o recurso mais importante do sistema empresa" (VIANA; CARDOSO 2012, p. 8). Quando se trabalha pensando nas pessoas, no conhecimento que elas possuem e o quão pode ser explorado o seu potencial, pode-se notar quais pessoas tem potencial para crescimento. 
Os indicadores na perspectiva de aprendizado e conhecimento relevantes são: nível de satisfação dos funcionários, retenção ou rotatividade de funcionários, lucratividade por funcionários, capacitação e treinamento dos funcionários, porcentagem de vendas oriundas de produtos novos e participação dos funcionários com sugestões para redução de custos ou aumento de receitas (WERNKE; BORNIA, 2001).

Quando se tem todas as informações desses indicadores, se consegue fazer um mapeamento de quais pontos devem ter um foco maior e qual está sendo executado conforme o planejado na decisão estratégica anterior.

Perspectiva de Processos Internos

$\mathrm{Na}$ perspectiva de processos internos, se podem verificar quais pontos não financeiros norteiam o rumo interno da empresa. Neste ponto os gestores fazem uma avaliação de tudo que ocorre internamente na empresa, buscando detectar quais são os pontos que travam a empresa. Para Kaplan e Norton (1997) a perspectiva de processos internos, procura os pontos que não permitem alcançar a excelência, quando isso ocorre, devem ser oferecidas ao conjunto direto propostas que trabalhem a captação de clientes e a satisfação, atingindo por meio desses pontos um resultado positivo financeiramente.

A perspectiva de processos mostra quais são os processos e seus objetivos, visando atender sempre o cliente e melhorar o desenvolvimento interno, fazendo que o os resultados financeiros demonstrem quais as consequências das estratégias adotadas.

Segundo Kaplan e Norton (1997) no BSC os executivos devem definir uma cadeia de valor completa dos processos internos, sendo os passos: o processo de inovação, processos de operações e serviços pós-venda.

Quando se fala da perspectiva de processos internos já aplicada na implantação do BSC, as empresas devem ficar atentas a pequenos serviços que ela pode implantar internamente, mas que reflitam externamente a ela, como serviço de pós-venda, pesquisa de mercado para necessidade de clientes existentes ou demanda que possam atrair clientes novos para a carteira. Para tanto esses atos devem ser reconhecidos pelos clientes.

Perspectiva de Clientes

A perspectiva de clientes surge para proporcionar aos diretores da empresa um panorama de como os clientes estão vendo a instituição. Permite que seja feito todo um mapeamento dos clientes e seus segmentos. Para Kaplan e Norton (1997, p. 26) existem medidas que devem ser notadas com foco no cliente: a satisfação, a retenção, a aquisição de novos, a lucratividade e a participação em contas destes. Quando se adotam essas medidas, a empresa consegue fazer uma identificação de quais pontos devem ser trabalhados e qual se encontram em um patamar aceitável, resultando para a instituição dados que mostram qual esta sendo a medida que mais consegue trabalhar o cliente e gera resultados positivos.

Fazer a medição da participação de mercado da empresa é um dos passos que deve ser adotado quando da perspectiva de clientes, trabalhar a retenção de clientes é um ponto que afeta muito o resultado das outras perspectivas, quando os negócios dos clientes crescem e a movimentação com a empresa também, isso é um sinal que o objetivo que foi estabelecido está sendo executado corretamente.

Captação de clientes é um processo que demanda muito entendimento do mercado que se encontra, trabalhar com produtos inovadores, que busque atender clientes e não clientes é um recurso muito utilizado para se captar novos clientes, pesquisas de mercado auxilia muito nesse processo. Medir a satisfação dos clientes gera uma informação muito preciosa para a 
empresa, o feedback que se obtém fazendo a medição pode ser usado para várias tomadas de decisão, sendo essa informação uma das mais importantes dentro da perspectiva.

Nada adianta ter bons resultados nos quatro indicadores descritos acima se o cliente não obtiver lucro com o produto que comprou, pois causa uma diminuição nos outros indicadores. Para evitar que isso ocorra, a empresa deve trabalhar com preço competitivo, prazo para pagamento e qualidade no produto. Quando existe harmonia entre esses acontecimentos, os clientes ficam satisfeitos e o reflexo se dá nas finanças da empresa.

Destaca-se que “[...] identificar os fatores importantes na concepção dos clientes é uma exigência do BSC e que as preocupações dos clientes comumente situam-se em torno de quatro categorias: tempo, qualidade, desempenho e serviço" (WERNKE; BORNIA, 2001, p. 8). Os fatores importantes para trabalhar a perspectiva de clientes no BSC, devem ser avaliadas e analisadas constantemente, pois quando se trabalha com mais de um fator, algumas mudanças podem resultar em um desequilíbrio em outras partes. Segundo Costa (2008) a forma de aumentar a participação no mercado é vendendo mais para os clientes atuais de cada segmento e atraindo novos consumidores.

Aumentar as vendas sem uma retenção de clientes, ou criar um novo produto sem uma pesquisa de aceitação ou de necessidade do mercado é uma decisão que trará consequências negativas a empresa, porém, quando se faz uma análise do mercado e principalmente de seus clientes, a empresa consegue ter uma visão de quais são as necessidades dos seus clientes e quais são seus potenciais clientes.

\section{Perspectiva Financeira}

A perspectiva financeira trabalha os resultados que são obtidos através da implantação e execução das outras perspectivas, nela é possível analisar qual a lucratividade ou no prejuízo. Quando Kaplan e Norton criaram o BSC, a medida de desempenho das informações financeiras era a mais utilizada pelos administradores e gestores das empresas. Através delas eram tomadas as decisões sem ter o conhecimento de quais eram as dificuldades da empresa, assim como de qual era a necessidade do cliente e se os funcionários estavam conseguindo se dedicar em sua totalidade para o cumprimento da função. " "[...] as medidas financeiras indicam se a estratégia da empresa, sua implementação e execução contribuem para a melhoria do resultado financeiro" (WERNKE; BORNIA, 2001, p. 8).

Quando se segue o planejado, implementando um modelo de gestão corretamente, a execução do planejado ocorre de maneira simples e a estratégia é seguida. A perspectiva financeira também é a mais importante do BSC para Viana e Cardoso (2012, p. 7), que especificam "por meio desta se pode quantificar em números, se a situação da empresa está de acordo com o planejamento e se caso haja algum desvio o gestor deverá tomar as devidas providências para corrigir".

A partir do momento em que se pode quantificar os resultados que estão sendo gerados em consequência de todas as outras perspectivas, nota-se que é possível fazer uma mensuração de quais pontos seguem o planejado e qual deve ser corrigido para que se possa alcançar o máximo de riqueza. Os objetivos financeiros, segundo Kaplan e Norton (1997, p. 49), "servem de foco para os objetivos e medidas de outras perspectivas do scorecard. Qualquer medida selecionada deve fazer parte de uma cadeia de relações de causa e efeito que culminam com a melhoria do desempenho financeiro".

Todas as perspectivas estão interligadas direta ou indiretamente, e todos os seus resultados refletem na área financeira, tanto para lucro ou prejuízo, quando se detecta alguma anormalidade no desempenho do conjunto, cabe ao responsável fazer a adequação para que o ciclo da empresa seja executado corretamente. 


\section{Mapas Estratégicos}

Mapas estratégicos é uma ferramenta que auxilia na elaboração do BSC, que proporciona uma visão das quatro perspectivas que fazem parte do modelo de gestão. Para (BRAGA; ALMEIDA; DA SILVA, 2005, p. 12) "O Balanced Scorecard possibilita a criação de mapas estratégicos que permitirão a avaliação de desempenho empresarial e a condução da gestão estratégica [...]". Quando se consegue desenvolver um mapa estratégico é possível através dele fazer a avaliação do sistema, determina ainda que a estratégia que foi adotada no início da implantação do sistema gerencial está conseguindo atingir seu objetivo.

Martins (2015) desenvolveu uma proposta de mapa estratégico para uma universidade pública, sendo o objetivo do trabalho a proposta de um BSC para a Universidade Estadual do Oeste do Paraná. A pesquisa é classificada como exploratória, para a elaboração do mapa levouse em consideração a finalidade pública da instituição, sendo alocado no topo do mapa estratégico a perspectiva educacional e não a financeira como normalmente acontece em empresas privadas. Todas as perspectivas devem ser trabalhadas de modo que o processo consiga alcançar os objetivos. Foram adotadas algumas modificações no modelo de mapa desenvolvido, foi acrescentado uma perspectiva pertinente para a análise das informações que foram apresentadas com as metas estabelecidas denominada educacionais e modificou-se a perspectiva de clientes para sociedade. A sequência das mesmas foi: educacional, financeira (verba disponibilizada para a universidade), sociedade, processos internos e aprendizado e crescimento, tendo como resultado do trabalho a percepção de um bloqueio cultural da organização, ocasionando uma dificuldade na execução e coleta de resultados.

Para Costa (2008), a finalidade do mapa estratégico é decodificar os processos complexos os quais enfrentam os gestores. Este também auxilia a administração a monitorar o cumprimento da estratégia e operacionaliza a vinculação do planejamento estratégico e o planejamento operacional.

Quando a implantação do mapa estratégico e o alinhamento do planejamento operacional com o estratégico, tanto os diretores quanto os funcionários da empresa trabalham com a mesma visão, buscando sempre o resultado positivo para a empresa.

O grande diferencial do mapa estratégico diante de outras opções é a apresentação de todas as informações geradas em um único relatório, envolvendo as quatro perspectivas do BSC. Segundo Kaplan e Norton (2004 apud LUNKES et al., 2009, p. 5) os mapas estratégicos "proporcionam aos empregados uma percepção clara de como suas funções estão ligadas aos objetivos gerais da organização, possibilitando que trabalhem de maneira coordenada e colaborativa em prol das metas almejadas pela empresa".

Mostrar aos colaboradores qual o seu papel e qual o impacto da sua função nas metas que foram estabelecidas, gera no empregado vontade de colaborar para que as metas sejam alcançadas, com isso o desenvolvimento da empresa se mantém em um ritmo estipulado.

Quando se faz a análise do exemplo de mapa estratégico apresentado na Figura 1, notase que cada perspectiva tem uma influência nas outras, sendo que isso está de acordo com a proposta que Kaplan e Norton tentam disseminar. Quando começa a se fazer um reconhecimento de cada perspectiva, começando pela de aprendizado e crescimento, é notável que todas as ações que fazem parte dela causam algum impacto nos processos internos, que sendo executado com as melhorias que são expostas no mapa, causam mudanças nos clientes, conseguindo ser atingido os propósitos dessa perspectiva, por último temos a perspectiva financeira, sendo esta a linha que mostra se todas as decisões que foram adotadas e os objetivos definidos estão trazendo resultados financeiros positivos para a empresa. 
Figura 1: Mapa estratégico do escritório de contabilidade

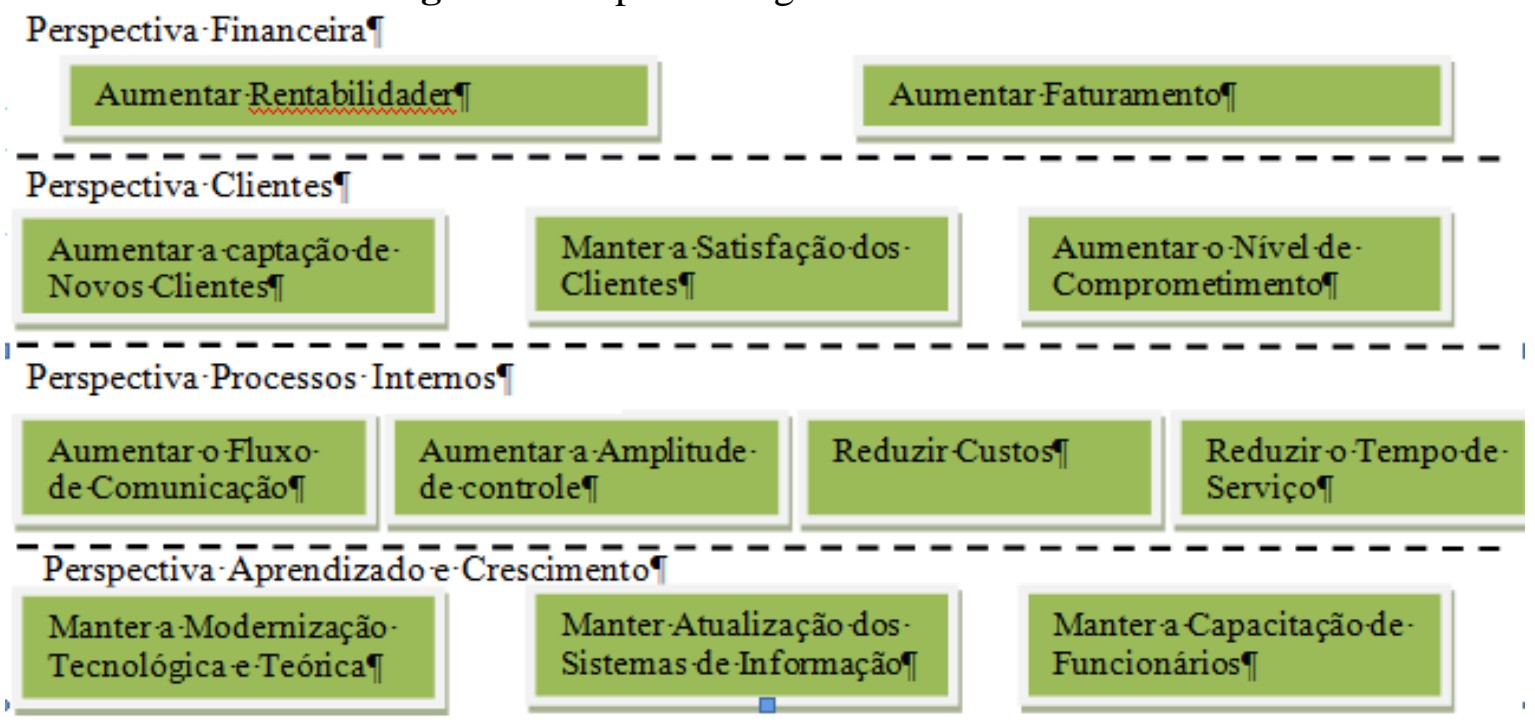

Fonte: Vieira, Petri (2014, p.5)

\section{PROCEDIMENTOS METODOLÓGICOS}

Levando em consideração as particularidades deste trabalho, quanto aos objetivos é uma pesquisa descritiva, pois tem como foco analisar como o Balanced Scorecard de uma empresa está elaborado em relação ao modelo proposto pelos criadores do método de gestão. Por analisar a situação da empresa definida se caracteriza como estudo de caso, fazendo uso de pesquisa documental. No que tange o quesito de abordagem é qualitativa, pois foi empregada uma análise de um modelo de gestão que se encontra implantado com as ideias dos criadores desse modelo.

Para ser realizada esta pesquisa, foi solicitado à empresa de siderurgia, para que a mesma forneça o Balanced Scorecard que ela utiliza.

Ocupando atualmente a $8^{\circ}$ colocação no cenário mundial na produção de aço, o setor de siderurgia no Brasil faturou mais de $\mathrm{R} \$ 68,7$ bilhões no ano de 2015 , demonstrando a força de um setor que em 2012 foi responsável por 4\% do PIB brasileiro. No ano de 2016, as empresas de siderurgia tinham mais de 100mil funcionários efetivos trabalhando no setor, sendo esses empregos gerados mais na região sudeste, que registra a maioria das industrias de produção no Brasil. O Brasil hoje possui 11 grupos empresariais que atuam no setor de siderurgia, a empresa analisada possui a sua sede no Brasil localizada em Porto Alegre - RS, porém a maioria das unidades de produção de aço estão localizadas na região Sudeste do país, por estar em áreas privilegiadas do território nacional que propicia uma maior produção, a empresa analisada ocupa a $10^{\circ}$ posição no ranking mundial de produção de aço, segundo a CNM. A escolha da empresa se deve pela representatividade que ela tem tanto para a economia nacional quanto a concorrentes estrangeiros.

A empresa que participa desta pesquisa ocupa a $10^{\circ}$ colocação no ranking mundial de produção de aço e a $2^{\circ}$ no nacional. Atua no ramo de siderurgia desde 1901, a empresa possui mais de 110 anos de atividade no Brasil e mais de 30 em diversos países do mundo, com a sua sede localizada em Porto Alegre no estado do Rio Grande do Sul, a corporação vem trabalhando na extração e mineração de aço, oferecendo produtos que atendem a construção civil, indústria, setor agropecuário, automotivo, entre outros setores da economia. Ingressando no mercado de capitais na década de 40 com a abertura do capital na bolsa de Porto Alegre e em 1999 inicia 
suas operações na Bolsa de Valores de Nova York. No ano de 2016 contando com mais de 31 mil colaboradores espalhados por todo mundo, que conseguiram gerar no ano de 2016 uma receita líquida de $\mathrm{R} \$ 38$ bilhões de reais, gerando um lucro líquido consolidado ajustado de $\mathrm{R}$ \$91 milhões. Em função da força que a empresa tem na economia nacional o Balanced Scorecard se faz necessário para auxiliar na gestão de uma empresa desse porte.

A coleta de dados foi realizada através de uma solicitação via e-mail do Balanced Scorecard da empresa, sendo concedido mediante o acordo da não divulgação do nome da empresa, por isso se faz uso neste trabalho do nome XYZ como fantasia.

\section{ANÁLISE E DISCUSSÃO DOS DADOS}

\section{Balanced Scorecard da Empresa}

O Balanced Scorecard da empresa estudada foi solicitado com objetivo de realizar uma análise e comparação com o BSC desenvolvido por Kaplan e Norton. Iniciaram-se os estudos verificando como empresa elaborou o seu BSC, quais características foram focadas e quais os pontos trabalhados, conforme se pode observar na Figura 2.

Figura 2: Implementando a Estratégia

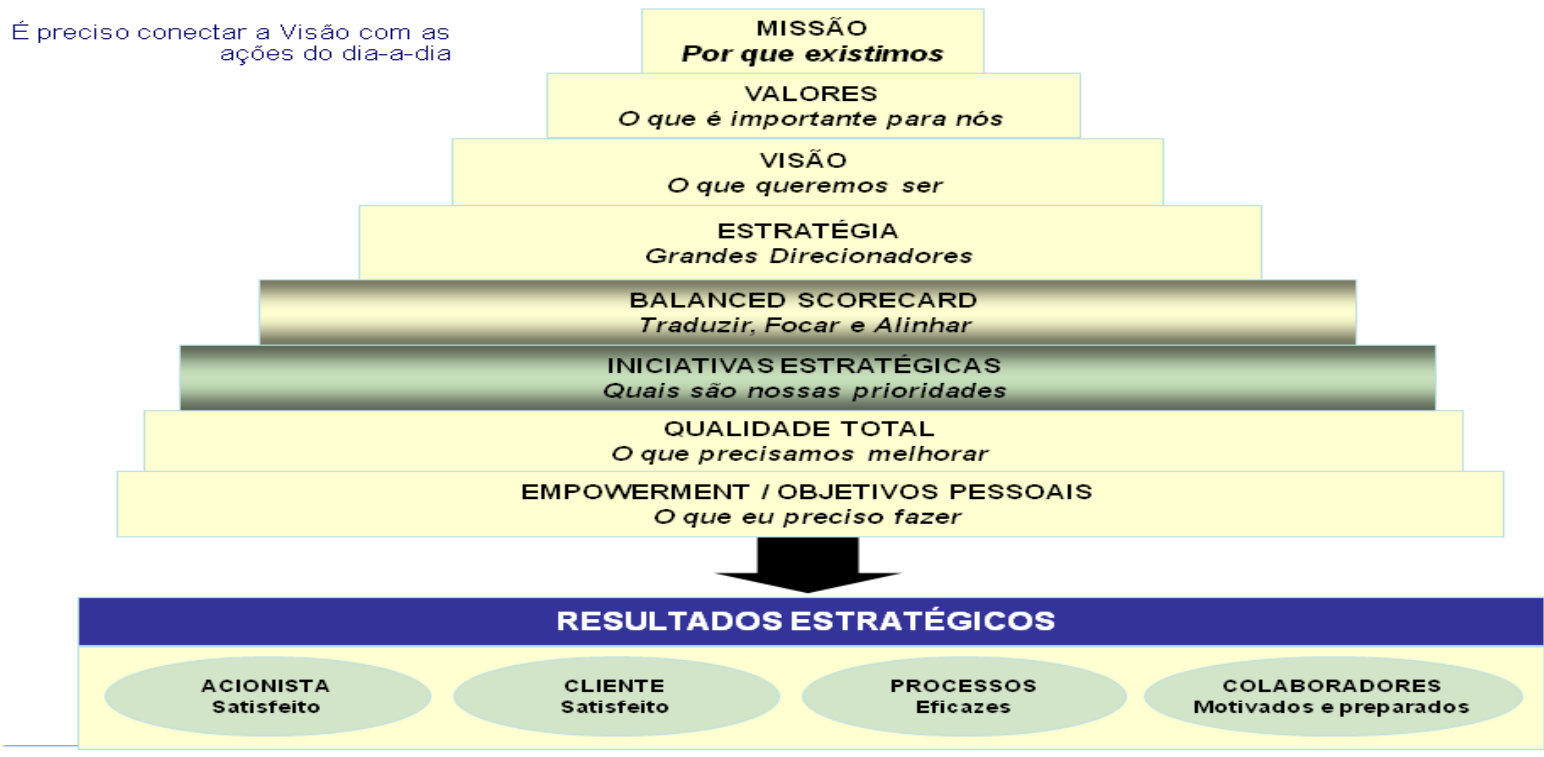

Fonte: Dados da empresa (2017)

A primeira análise que se pode identificar na leitura da implementação da estratégia que a empresa utilizou, mostra que ela trabalhou com o processo em cadeia, tendo como início de todas as etapas a missão da empresa, que deve mostrar a razão de existência e qual a sua função. A segunda etapa foi trabalhar com os valores, sendo definido nesse ponto o que é importante para a instituição. Trabalhando em seguida com a visão que deve ser adotada, sendo implantada com o intuito de elaborar como querem ser vistos.

Após essas definições, começa a tarefa de definir as estratégias, onde foram escolhidas as direções que a empresa deve seguir e quais rumos tomar. Depois de definir essa etapa, inicia a elaboração do BSC, sendo utilizado para determinar os objetivos que devem ser alcançados e alinhar as estratégias definidas anteriormente. Utilizando o BSC para demonstrar isso, se faz uso de iniciativas estratégicas, gestão da qualidade total e a elaboração de objetivos pessoais. Como resultado da implantação desse processo, a empresa XYZ esperava atingir os seguintes 
resultados estratégicos: acionistas satisfeitos, clientes satisfeitos, processos eficazes e colaboradores motivados e preparados.

Analisando a metodologia desenvolvida por Kaplan e Norton, percebe-se que foram atendidas as premissas de elaboração da missão, visão e valores. O desenvolvimento das estratégias utilizadas, juntamente com as etapas trabalhadas, mostra que todo o processo foi composto com base na metodologia de Kaplan e Norton. O passo seguinte, na estratégia da XYZ foi a elaboração do planejamento e gestão estratégica, descrito a seguir na Figura 3.

Figura 3: Planejamento e Gestão da Estratégia

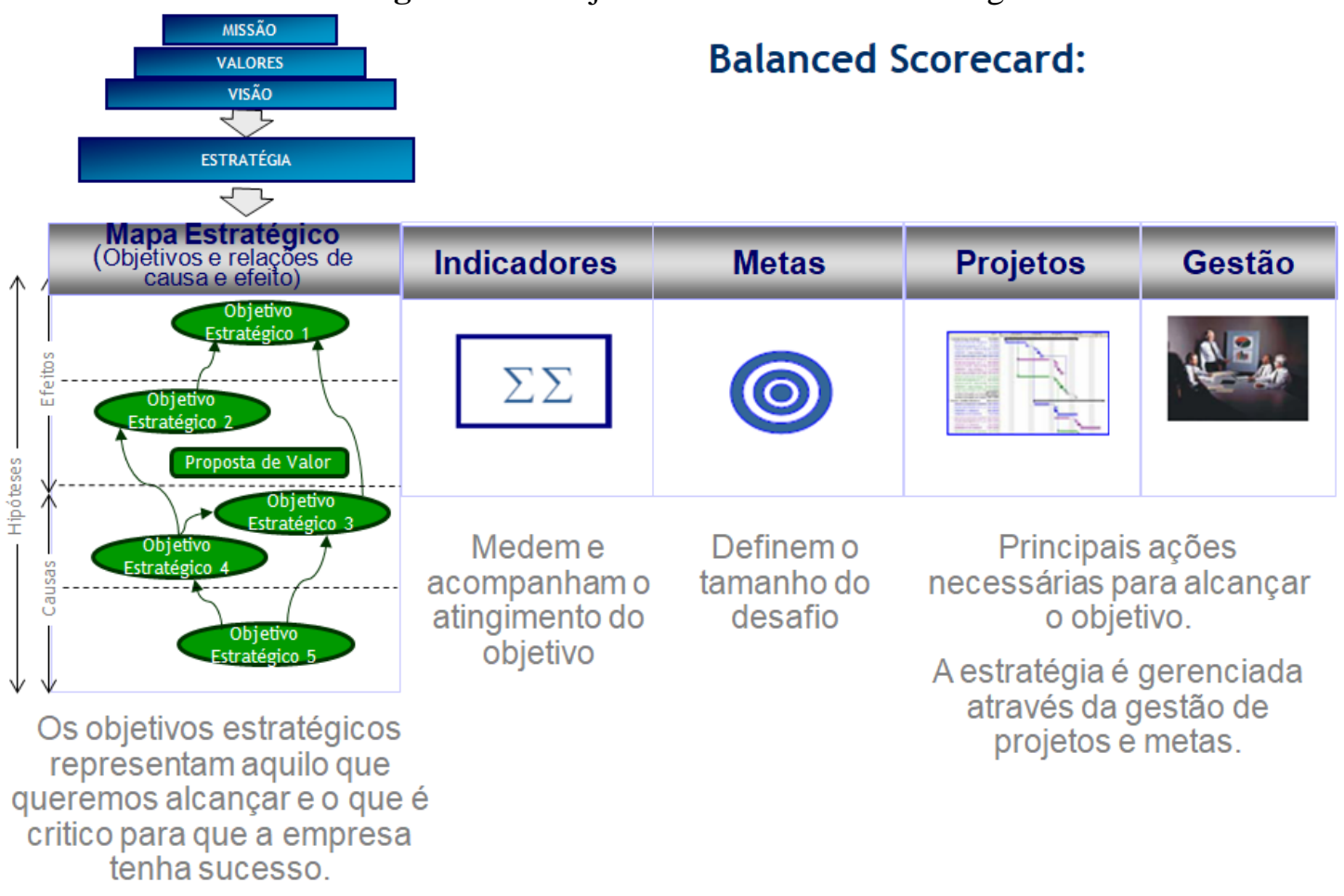

Fonte: Dados da empresa (2017)

$\mathrm{Na}$ parte da gestão estratégica, se fez uso da ferramenta mapa estratégico, sendo utilizada para demonstrar os objetivos que devem ser alcançados e quais os pontos críticos que necessitam de auxílio, com o propósito de atingir o sucesso do planejamento. Como ferramentas que auxiliam na medição do mapa estratégico, os indicadores servem para demonstrar com números, como está sendo executado e quais pontos já atingiram seus níveis desejados.

Para se atingir os objetivos devem ser elaboradas metas, sendo feito o detalhamento do tamanho do desafio que será proposto para todos que colaboram na empresa XYZ. Para que todos estes instrumentos apresentados sejam utilizados da melhor maneira possível, a empresa adotou um sistema de gestão e projetos, que realiza o acompanhamento da estratégia, fazendo as medições com os indicadores e acompanhando as metas que são estabelecidas, tendo como resultado final o mapa estratégico ajudando a gestão da empresa.

A elaboração do mapa estratégico trabalhando: as influências das quatro perspectivas dentro do processo, a utilização de indicadores e metas, a implementação de projetos e gestão destes, mostrou que foram seguidos todos os passos essenciais para a implantação de um BSC segundo os princípios de Kaplan e Norton.

Após esta etapa, a empresa XYZ trabalhou os desdobramentos da estratégia para o operador industrial, conforme Figura 4. 


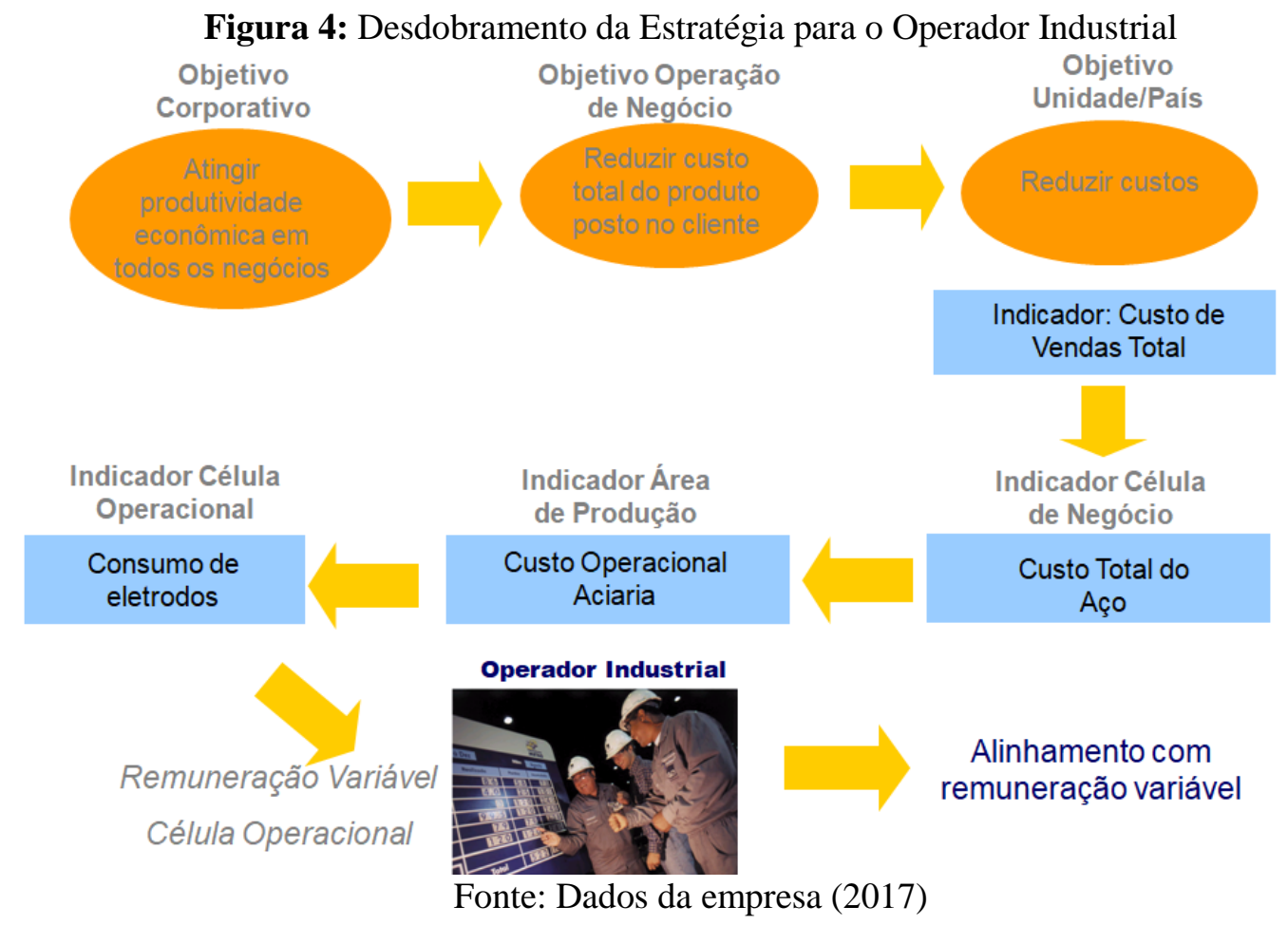

Fazendo uso de diversas metas, a estratégia apresentada visa atingir várias etapas e objetivos que devem ser alcançados com a execução das mesmas. Estas foram trabalhas individualmente, mas sempre pensando no resultado conjunto no final do processo. No trabalho de objetivo corporativo, a XYZ trabalha com a intenção de atingir a produtividade econômica em todos os negócios que são operados pela mesma.

O objetivo da operação de negócio está sendo elaborado com o propósito da redução do custo total do produto que será repassado ao cliente, o corte do custo também será adotado como objetivo das unidades em operação, como forma de medir o resultado das políticas adotadas será utilizado o indicador: custos de vendas totais; será utilizado como base de informações e medição. Outros indicadores que farão parte do processo de medir o desempenho da estratégia adotada são: indicador célula de negócio que medirá o custo do aço no processo, indicador área de produção será utilizado para mensurar o custo operacional aciaria, indicador célula operacional monitorará o consumo de eletrodos no processo de produção, como base final de todo o processo será adotado o critério de remuneração variável, que impactará diretamente no operador industrial, causando um alinhamento na forma de remuneração.

Análise do Balanced Scorecard da Empresa

A metodologia que Kaplan e Norton adotam para a elaboração do BSC trabalha as quatro perspectivas que foram desenvolvidas para dar uma maior amplitude nos índices e dados que as empresas devem analisar, fazendo uma leitura diferenciada dos dados que são apresentados. O BSC inicia o seu desenvolvimento com a montagem do mapa estratégico que trabalha ações que são desenvolvidas para as perspectivas fluírem de modo a proporcionar informações e resultados que são esperados com a implantação desse sistema de gestão.

Analisando a perspectiva de aprendizado e crescimento, a empresa XYZ adota apenas a meta de alinhar junto aos colaboradores a política da remuneração variável, sendo esse o objetivo dessa perspectiva, destaca-se que poderiam ser desenvolvidas mais metas se tratando de uma indústria, o que impactaria muito na sua produção e desenvolvimento de novos 
produtos, principalmente se tratando de um setor da economia que gera muitos empregos e movimenta financeiramente valor consideráveis, vide Figura 5.

Figura 5: Perspectiva de Aprendizado e Crescimento.

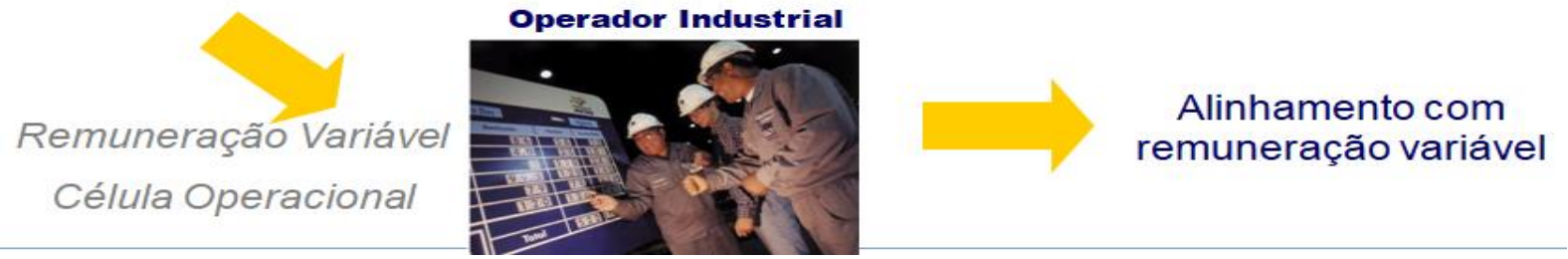

Fonte: Dados da empresa (2017)

No trabalho desenvolvido na perspectiva de processos internos, pode-se analisar uma decisão tomada de duas maneiras, a XYZ adota o critério da redução dos custos, essa meta pode ser encaixada nessa perspectiva quanto na financeira, sendo trabalhada como foco principal a redução dos custos para os clientes, para a própria empresa no seu processo de funcionamento, deixando espaço para outras metas serem desenvolvidas, sendo deixado de lado todo o potencial dessa perspectiva, conforme Figura 6.

Figura 6: Perspectiva de processos internos.

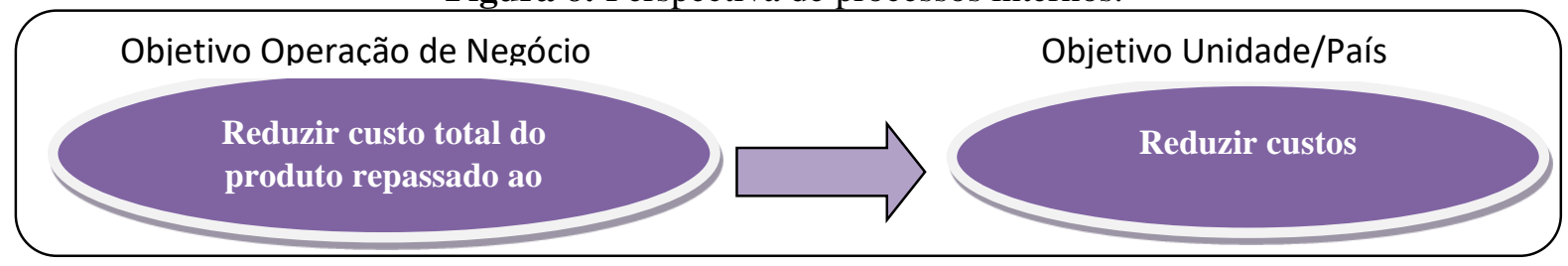

Fonte: Dados da empresa (2017)

A perspectiva de clientes não é tão bem trabalhada pela empresa, deixando de lado uma perspectiva que gera grandes informações estratégicas para decisões futuras. Para que o sistema consiga atingir os objetivos e metas estabelecidas, o cliente tem que fazer parte por ser quem compra; responsável pelo giro do estoque e o crescimento das receitas e lucro.

Por último, considerada como a principal perspectiva, a que todas as empresas querem ver são os números, conforme Figura 7. A perspectiva financeira que a empresa XYZ adota visa conseguir o resultado positivo para os acionistas, fazendo que eles estejam satisfeitos com as informações repassadas pela empresa para eles e para o mercado financeiro, sendo trabalhado apenas o resultado para os acionistas que fazem parte ou queiram fazer parte do capital da mesma. O quadro 1 apresenta um resumo comparativo das ações desenvolvidas pela empresa XYZ e a proposta de Kaplan e Norton

Figura 7: Perspectiva financeira.

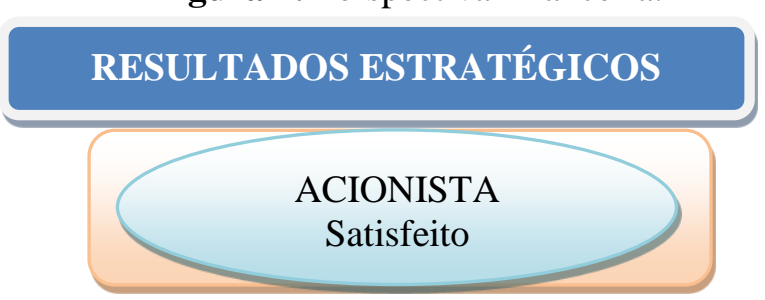

Fonte: Dados da empresa (2017) 
Quadro 1: Comparação das ações desenvolvidas

\begin{tabular}{|c|c|c|c|}
\hline \multicolumn{4}{|c|}{ COMPARAÇÃO DAS AÇÕES DESENVOLVIDAS } \\
\hline Perspectiva & $\begin{array}{l}\text { Metodologia de Kaplan } \\
\text { e Norton }\end{array}$ & Empresa XYZ & Reflete ou Não \\
\hline Financeira & $\begin{array}{l}\text { A perspectiva financeira } \\
\text { serve como um espelho } \\
\text { que reflete todo o projeto } \\
\text { desenvolvido, visando } \\
\text { descobrir se está sendo } \\
\text { executado conforme o } \\
\text { planejamento, sendo } \\
\text { disponibilizado } \\
\text { informações } \\
\text { demonstrem o resultado } \\
\text { atingido podendo ser } \\
\text { lucro ou prejuízo. }\end{array}$ & $\begin{array}{l}\text { A empresa XYZ, trabalha } \\
\text { a perspectiva financeira, } \\
\text { desenvolveu como } \\
\text { objetivo a busca da } \\
\text { geração de valor para os } \\
\text { seus acionistas. }\end{array}$ & $\begin{array}{l}\text { Analisando todo o } \\
\text { processo desenvolvido, } \\
\text { chega-se a conclusão que } \\
\text { a perspectiva financeira } \\
\text { reflete a metodologia } \\
\text { desenvolvida por Kaplan } \\
\text { e Norton, por se tratar de } \\
\text { uma empresa de capital } \\
\text { aberto, o objetivo } \\
\text { financeiro é a geração de } \\
\text { valor para os acionistas. }\end{array}$ \\
\hline Clientes & $\begin{array}{l}\text { A perspectiva de clientes } \\
\text { busca desenvolver } \\
\text { métodos para conseguir } \\
\text { medir como o produto ou } \\
\text { serviço disponibilizado } \\
\text { influência nas empresas } \\
\text { que fazem uso dos } \\
\text { mesmo, visando sempre a } \\
\text { retenção e aceitação do } \\
\text { mercado, investindo em } \\
\text { pesquisas que busquem } \\
\text { descobrir a necessidade } \\
\text { do mercado para o futuro } \\
\text { e desenvolvendo } \\
\text { ferramentas para } \\
\text { conquista de mercados } \\
\text { que não fazem parte da } \\
\text { área atendida. }\end{array}$ & $\begin{array}{l}\text { A perspectiva de clientes } \\
\text { foi trabalhada focando na } \\
\text { redução do custo total do } \\
\text { produto repassado no } \\
\text { cliente. }\end{array}$ & $\begin{array}{l}\text { O objetivo estabelecido } \\
\text { para a perspectiva de } \\
\text { clientes reflete a proposta } \\
\text { de Kaplan e Norton, pois a } \\
\text { disponibilidades de um } \\
\text { produto com custo menor } \\
\text { torna o produto do cliente } \\
\text { mais atrativo ao mercado. }\end{array}$ \\
\hline Interna & $\begin{array}{l}\text { A perspectiva de } \\
\text { processos internos, busca } \\
\text { desenvolver métodos que } \\
\text { tornem os processos } \\
\text { internos eficazes, sendo } \\
\text { sugerido a implantação de } \\
\text { uma cadeia de valor, } \\
\text { evidenciando que atitudes } \\
\text { internas reflitam em } \\
\text { outras perspectivas, } \\
\text { trabalhando sempre } \\
\text { visando que mudanças } \\
\text { internas sejam refletidas } \\
\text { positivamente para os } \\
\text { clientes. }\end{array}$ & $\begin{array}{l}\text { A perspectiva interna teve } \\
\text { como objetivos } \\
\text { estabelecidos a meta de } \\
\text { conseguir r uma } \\
\text { produtividade econômica } \\
\text { em todos os negócios que } \\
\text { a empresa XYZ atua, a } \\
\text { redução de custos de } \\
\text { maneira geral, } \\
\text { estabelecendo indicadores } \\
\text { que demonstrem a } \\
\text { situação. }\end{array}$ & $\begin{array}{l}\text { As } \\
\text { estabelecidas propostas } \\
\text { perspectiva interna } \\
\text { atendem a metodologia de } \\
\text { Kaplan e Norton, } \\
\text { buscando maneiras de } \\
\text { conseguir uma redução } \\
\text { dos custos da produção, } \\
\text { fazendo a medição das } \\
\text { informações com } \\
\text { indicadores estabelecidos } \\
\text { pela empresa. }\end{array}$ \\
\hline
\end{tabular}




\begin{tabular}{|c|c|c|c|}
\hline $\begin{array}{l}\text { Aprendizado } \\
\text { e } \\
\text { Crescimento }\end{array}$ & $\begin{array}{l}\text { A proposta de Kaplan e } \\
\text { Norton para a perspectiva } \\
\text { de aprendizado e } \\
\text { crescimento, busca } \\
\text { implementar que as } \\
\text { empresas passem a } \\
\text { investir mais em seus } \\
\text { colaboradores, } \\
\text { comecem a valorizar mais } \\
\text { o capital intelectual dos } \\
\text { funcionários, visando } \\
\text { sempre a valorização do } \\
\text { colaborador. }\end{array}$ & $\begin{array}{lr}\text { Trabalhando } & \text { a } \\
\text { perspectiva } & \text { de } \\
\text { aprendizado } & \mathrm{e} \\
\text { crescimento, a empresa } \\
\text { XYZ adotou a ideia da } \\
\text { remuneração variável a } \\
\text { seus colabores da área } \\
\text { industrial. }\end{array}$ & $\begin{array}{l}\text { Analisando o r objetivo } \\
\text { estabelecido } \\
\text { perspectiva } \\
\text { aprendizado na } \\
\text { crescimento, nota-se que a } \\
\text { empresa XYZ reflete o } \\
\text { trabalho de Kaplan e } \\
\text { Norton, buscando uma } \\
\text { integração } \\
\text { colaboradores com os } \\
\text { objetivos estabelecidos } \\
\text { nas outras perspectivas, } \\
\text { sendo aplicado no salário. }\end{array}$ \\
\hline
\end{tabular}

Fonte: Elaborado pelos autores (2017)

O Quadro 1 busca demonstrar como as quatro perspectivas devem ser desenvolvidas com base na metodologia de Kaplan e Norton, como foi estruturado pela empresa XYZ, fazendo uma análise no final demonstrando se as ações adotadas refletem ou não as ideias dos autores para o alcance de resultados estratégicos. Quando se analisa a primeira imagem apresentada no BSC da empresa XYZ, percebe-se que a mesma busca trabalhar as quatro perspectivas, tendo como objetivos acionistas satisfeitos, clientes satisfeitos, processos eficazes e colaboradores motivados e preparados para o trabalho, sendo que isso não chega a ser trabalhado por completo pelo mapa estratégico da empresa, sendo totalmente diferente do modelo apresentado no livro de Kaplan e Norton, conforme Figura 8.

Figura 8: Resultados estratégicos

\section{RESULTADOS ESTRATÉGICOS}

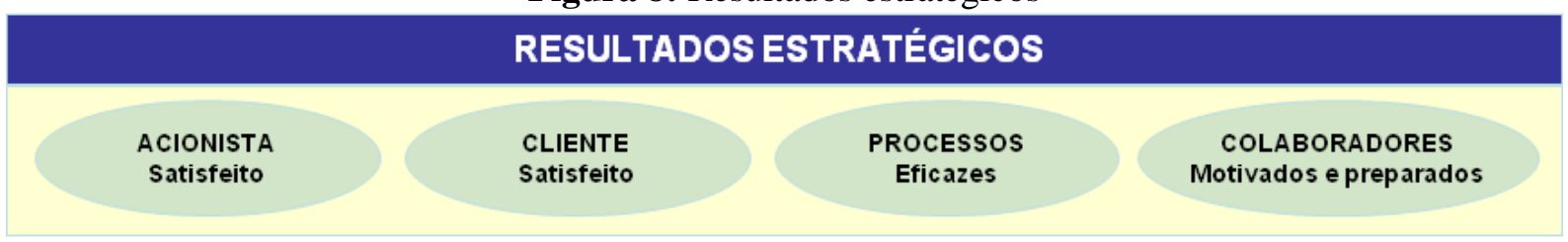

Fonte: Dados da empresa (2017)

Na Figura 9 fica visível o trabalho das quatro perspectivas, de modo que fica evidente que determinadas atitudes em alguma perspectiva terá impacto sobre outra perspectiva, positivamente ou negativamente. O objetivo é ser elaborado de forma a sempre melhorar o desempenho e os processos pelos quais cada perspectiva trabalha, conseguindo assim uma melhor distribuição das tarefas e objetivos, para visualizar os resultados individualmente e coletivamente, possibilitando fazer mudanças pontuais com o objetivo de alcançar as metas estabelecidas no planejamento estratégico. Analisando as quatro perspectivas da Figura 9, percebe-se que atitudes que são vistas de forma positivas agilizam todo o processo e o resultado, a perspectiva de aprendizado e crescimento demonstra claramente isso, funcionários motivados e que são ouvidos pela empresa sempre buscam dar sugestões aos seus superiores, fazem menos retrabalho, gerando uma positividade na satisfação dos clientes que recebem seus produtos ou serviços com a qualidade desejada e dentro do tempo que esperam, resultando com que as vendas cresçam e aumente o saldo de contas a receber, e aumentando o retorno do capital empregado no negócio. Menos retrabalho também reduz o valor das despesas operacionais, quando acontece de o trabalho ter que ser refeito, as despesas sobem consideravelmente e o 
retorno do capital empregado diminui, fazendo com que a empresa tenha um lucro menor do que o desejado.

Figura 9: Echo Engineering - Vinculação de Indicadores das Quatro Perspectivas

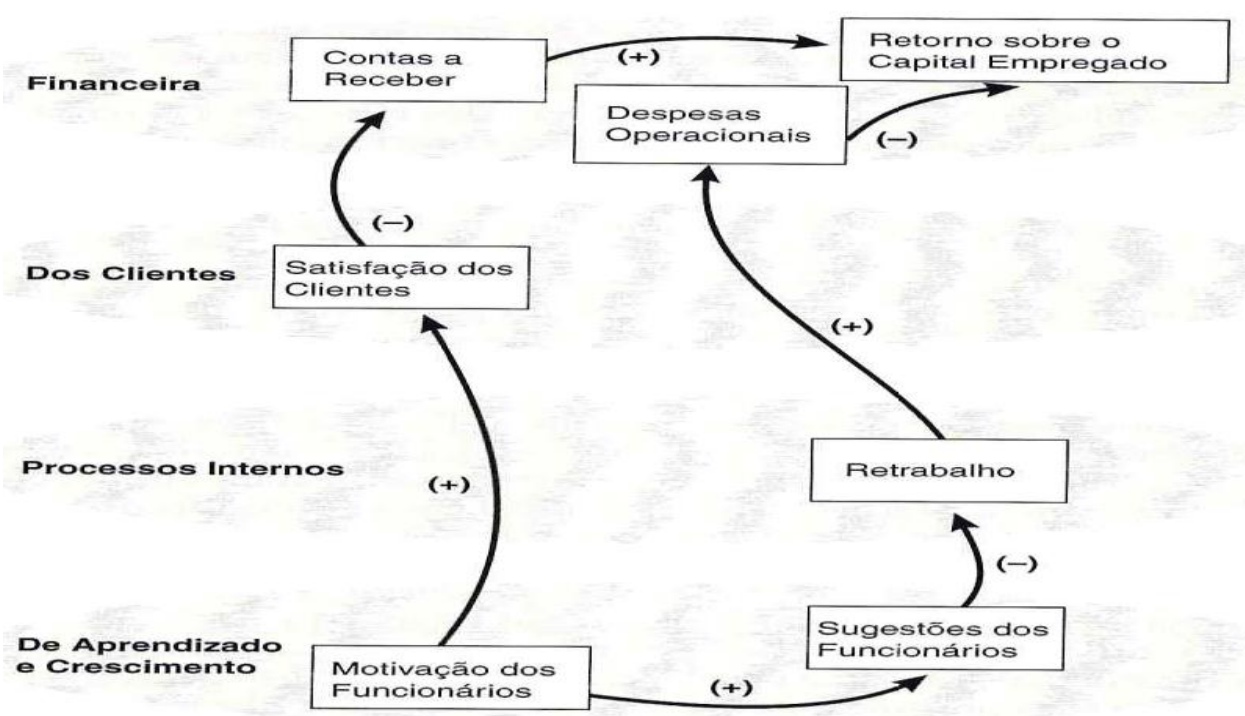

Fonte: Kaplan e Norton; (1997, p. 267).

A Figura 10 é mapa estratégico desenvolvido pela empresa.

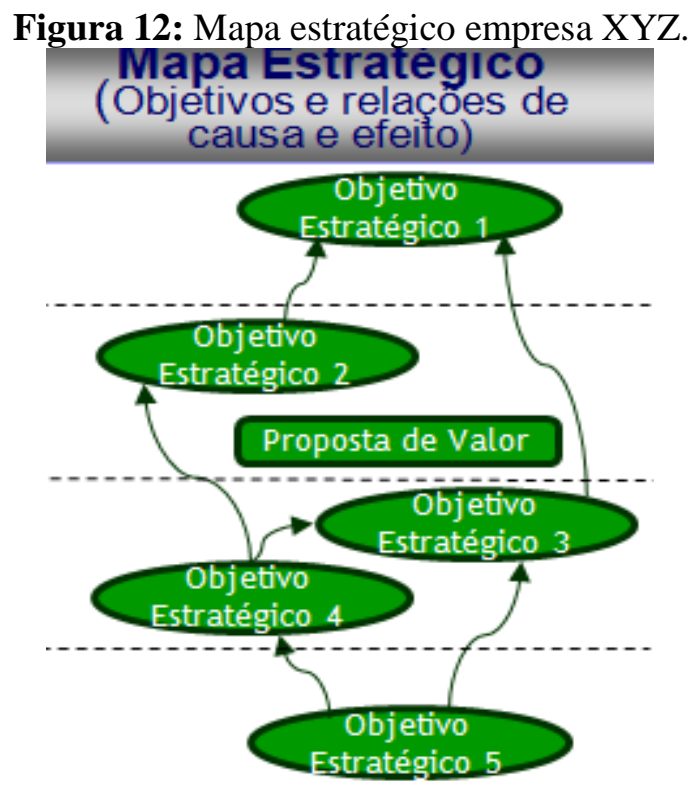

Fonte: Dados da empresa (2017).

Quando se comparam as duas Figuras 9 e 10, nota-se que o mapa desenvolvido pela empresa XYZ adota em alguns critérios as ideias de Kaplan e Norton, com objetivos sendo estabelecidos dentro das quatro perspectivas trabalhadas, mostrando a influência de cada objetivo no próximo em outra perspectiva, sendo mostrada inclusive a intenção de gerar valor 
para os clientes da empresa, buscando sempre o objetivo principal que se encontra na perspectiva financeira.

\section{CONCLUSÕES}

As empresas nos tempos atuais valorizam muito às informações que obtém através dos sistemas de gestão existes. O Balanced Scorecard, sistema de gestão estudado que apresenta informações relativas a pessoas, processos internos, clientes e financeira, abre um leque de informações e áreas que são analisadas. Desta forma, empresas que utilizam sistemas que geram dados constantes e que conheçam qual caminho seguir com essas informações em mãos conseguem uma vantagem em relação aos concorrentes.

A problemática apresentada neste estudo busca analisar se o BSC adotado pela empresa XYZ se encontra em conformidade com a metodologia de Kaplan e Norton, sendo utilizado o método de comparação das informações disponibilizadas e a literatura dos autores especializados no assunto.

Fazendo uso da interpretação e análise das informações disponibilizadas pela XYZ, observou-se que os objetivos que a proposta de BSC tinha, o mapa desenvolvido para esquematizar os objetivos, as decisões tomadas para cada uma das quatro perspectivas trabalhadas pela empresa, fazendo a leitura e comparação com todas as informações disponíveis da metodologia trabalhada por Kaplan e Norton. Com base nas análises feitas, comprova-se que o BSC desenvolvido e aplicado pela empresa XYZ reflete a metodologia trabalhada por Kaplan e Norton, mostrando todo o trabalho de desenvolvimento e aplicação, desde a definição da missão, visão e valores, passando a definição da estratégia e criação do mapa estratégico, definindo posteriormente projetos aplicados a cada uma das quatro perspectivas. Concluindo que a empresa XYZ procedeu de acordo com as etapas para a estruturação do BSC conforme a metodologia de Kaplan e Norton.

\section{REFERÊNCIAS}

BRAGA, Lívia de Sá Lira Albuquerque; ALMEIDA, Sídia Fonseca; DA SILVA, Wilson Roberto. A Importância do Balanced Scorecard como base para um sistema de mediação e gestão estratégica de custo: um estudo de caso no setor de turismo de Campina Grande - PB. In: CONGRESSO INTERNACIONAL DE CUSTOS, IX, 2005, Florianópolis. Anais...Florianópolis, 2005.

BRASIL, Instituto Aço. Dados do Setor. 2015. Disponível em: <http://www.acobrasil.org.br/site2015/dados.asp> Acesso em: 23 jun. 2017.

COSTA, Ana Paula Paulino da. Balanced Scorecard: conceitos e guia de implementação. 1. ed. São Paulo: Atlas, 2008.

KALLÁS, David. Balanced Scorecard: aplicação e impactos. 2003. 217 f. Dissertação (Mestrado) - Curso de Administração, Universidade de São Paulo, São Paulo, 2003.

KAPLAN, Robert S.; NORTON, David P. A Estratégia em Ação. Rio de Janeiro: Elservier, 1997.

KIYAN, Fábio Makita. Proposta para desenvolvimento de indicadores de desempenho como suporte estratégico. 2001. 118 f. Dissertação (Mestrado em Engenharia de Produção) Escola de Engenharia de São Carlos, Universidade de São Paulo, São Carlos, 2001. 
HIKAGE, Oswaldo Keiji; SPINOLA, Mauro de Mesquita; LAURINDO, Fernando José Barbin. Software de balanced scorecard: proposta de um roteiro de implantação. Prod., São Paulo, v. 16, n. 1, p. 140-160, Apr. 2006.

LUNKES, Rogério João et al. Implementação do Balanced Scorecard em uma empresa de software. Pensar Contábil, v. 11, n. 45, 2009. Disponível em: <http://www.atena.org.br/revista/ojs-2.2.3-06/index.php/pensarcontabil/article/viewFile/3/3 > Acesso em: 21 jun. 2017.

MARTINS, Vinicius Abilio. Proposta de um Mapa Estratégico para uma Universidade Pública. In: Congresso USP de Controladoria e Contabilidade, 15., 2015, São Paulo. Anais... São Paulo: USP, $2015 . \quad$ Disponível em: $<$ http://www.congressousp.fipecafi.org/anais/artigos152015/an_resumo.asp?con=1\&cod_trab alho=299\&titulo=Proposta+de+um+Mapa+Estrategico+para+uma+Universidade+Publica. Acesso em: 06 set. 2017.

MORIM, Sandi Kelli; VARGAS, Sedenir Antonio de. Balanced Scorecard como instrumento de gestão estratégica na mensuração do desempenho das empresas do segmento siderúrgico listadas na BM\&F Bovespa. In: Congresso Brasileiro de Custos, 23., 2016, Porto de Galinhas. Anais... Porto de Galinhas: 2016. Disponível em: <https://anaiscbc.emnuvens.com.br/anais/article/view/4166/4167>. Acesso em: 21. jun. 2017.

OLIVEIRA, Djalma de Pinho Rebouças de. Planejamento Estratégico: conceitos, metodologia e práticas. 22. ed. São Paulo: Atlas, 2006.

PORTER, Michael. Estratégia Competitiva: técnicas para análise de indústrias e da concordância. Trad. Elizabeth Maria de Pinho Braga. 2. ed. Rio de Janeiro: Elsevier, 2004. 12a reimpressão.

RIBEIRO, Reoçoli. O Processo de Planejamento Estratégico: ações estratégicas e resultados - o caso da universidade de Passo Fundo. 2001. 142 f. Dissertação (Mestrado) - Curso de Administração, Universidade Federal de Santa Catarina, Florianópolis, 2001.

VIANA, Andson de Freitas; CARDOSO, Nemias Figueiredo, CONGRESSO USP DE CONTROLADORIA E CONTABILIDADE, 12², 2012, São Paulo. Implantação do Balanced Scorecard em operadoras de plano de saúde: estudo de caso. São Paulo, 2012.

WERNKE, Rodney; BORNIA, Antonio Cezar. Balanced Scorecard: considerações e comentários. In: CONGRESSO BRASILEIRO DE CUSTOS, 7., 2001, São Leopoldo. Anais...São Leopoldo, 2001. Disponível em: <https://anaiscbc.emnuvens.com.br/anais/article/view/2904/2904>. Acesso em: 12 jul. 2017. 